\title{
Reservoir Fluid Determination from Angle Stacked Seismic Volumes in 'Jay' Field, Niger Delta, Nigeria
}

\section{*ADEOTI, L; ALLO, OJ; AYOLABI, EA; AKINMOSIN, A; OLADELE, S; OYENIRAN, T; AYUK, MA}

Department of Geosciences, Faculty of Science, University of Lagos, Lagos, Nigeria

*E-mail address: lukuade@yahoo.com, ladeoti@unilag.edu.ng; Tel.: +2348034739175

\begin{abstract}
The study was carried out to investigate the dissimilar seismic amplitude responses observed in sandstone reservoirs with the same fluid saturation. This challenge now informed the analysis of different amplitude responses from the 'Jay' Field in order to verify the reservoirs fluids around and away from well location based on the integration of Amplitude Variation with Angle (AVA) and seismic inversions. The well log data provided were used to identify hydrocarbon bearing zones and Poisson Ratio analysis. Anomalies from the AVA analysis were investigated using the elastic impedance inversion of the near and far volumes. Crossplots of Lambda-Mu-Rho inversion were produced to relate reservoir incompressibility and rigidity modulus for lithology and fluid determination. Sand E exhibited amplitude increase with angles at well point and also away from well location (red triangle). The approximate elastic impedances of the inverted seismics are almost similar to the log estimates, an indication of good correlation. Integration of incompressibility (Lambda-Rho) and rigidity (Mu-Rho) modulus analyses reveals the presence of gas saturation in reservoir Sand G because low Lambda-Rho coincides with high Mu-Rho from both log estimates and inverted seismics. In the case of Sand D, high Lambda-Rho coincides with high Mu-Rho because it is oil saturated. This study has helped to differentiate the fluids in Sands D and G despite having similar AVA responses. The methods adopted in this work can be useful in hydrocarbon detection from seismic data in fields with similar geological setting.
\end{abstract}

DOI: https://dx.doi.org/10.4314/jasem.v22i4.2

Copyright: Copyright $@ 2018$ Adeoti et al. This is an open access article distributed under the Creative Commons Attribution License (CCL), which permits unrestricted use, distribution, and reproduction in any medium, provided the original work is properly cited.

Dates: Received: 17 January 2018; Revised: 07March: 2018; Accepted: 03 April 2018

Keywords: Amplitude Variation with Angles; Elastic Impedance; Near and Far offsets; Full stack seismic volume

Seismic inversion technique helps in the determination of reservoir properties away from well location (Simm, 2005). For instance, inverted seismic data enhances the identification of subtle properties in conventional seismics (Contreras et al., 2006). Reservoir properties between wells can be determined from inverted seismic results. This was demonstrated by Adekanle and Enikanselu, (2013) where the vertical and lateral extent of rock properties such are porosity, lithology and density were determined. However, seismic data have limited frequency content such that thin layers may not be resolved (Simm and Bacon, 2014).

The integration of high frequency log information with seismic data in model based inversion was adopted to mitigate this effect. Moreover, model based inversion technique of iterative forward modeling and comparison procedure does not suffer from defective wavelet and over simplification of the subsurface associated with recursive and sparse spike inversions methods respectively (Cooke and Schneider, 1983; Veeken and Da Silva, 2004; Simm and Bacon. 2014).
The integrated approach of Lambda-Mu-Rho inversion and Rock Physics modeling by Ekwe et al., (2012) was used to delineate hydrocarbon charged reservoirs in a Niger Delta field. In gas hydrates region where well information is most often sparse, Amplitude Variation with Angle (AVA) was the method used for free hydrate gas assessment as discussed by Javaherian et al., (2013). This work did not integrate other methods to substantiate the presence of gas in the field since the hydrate gas is situated at shallow depths. The result showed the presence of unique Class IV gas sand in this deep water block. However, in most of these studies, the observed high amplitude responses were not constrained to avoid seismic amplitudes from nonhydrocarbon sources that characterize poorly compacted sandstone reservoirs.

The study area falls within part of Niger Delta oil province where its Tertiary sediments are made up of three lithostratigraphic units distinguished mostly on the basis of sand - shale ratios; these are the Akata, 
Agbada and Benin formations. This Formation which is at the base of the delta is of marine origin and is composed of thick shale sequences that form potential source rocks and turbidite sand which are potential reservoirs in deep water settings (Stacher, 1995). The overlying Agbada Formation is the major petroleumbearing unit which began in the Eocene and continues into the Recent. The Agbada formation is made up of intercalations of sand and shale sequences. The sands are mainly unconsolidated reservoir sands while the shale serves as source and cap rocks. The Agbada Formation is overlain by the third formation, the Benin Formation, a continental Eocene to Recent deposit of alluvial and upper coastal plain sands that are up to $2000 \mathrm{~m}$ thick (Avbovbo, 1978). The study area shows that the young Tertiary sandstone sediments of the 'Jay' Field are characterized by poor compaction and prone to produce spurious amplitude reflections not diagnostic of hydrocarbon presence. This now has led to mapping bright spot caused by non-hydrocarbon saturation. Therefore, in this study, AVA analyses and model based seismic inversion techniques were integrated to reduce the risk associated with amplitude responses from poorly compacted sandstone reservoirs. This would in turn assist to reveal the type and extent of hydrocarbon presence with good certainty especially in areas far from well log information.

\section{MATERIALS AND METHODS}

Data gathering: The data set were obtained from Chevron through the Department of Petroleum resources (DPR). These include two well logs (Jay 01 and 02) in LAS format and three 3D seismic data in SEGY format. Well Jay 01 consists of Gamma, Psonic, Bulk density, Neutron porosity, Deep resistivity etc. of up to 14000 feet while well Jay 02 has Gamma, P-sonic, S-sonic, deep resistivity, Neutron porosity, Density etc. The seismic data include a full post-stack time migrated, a near angle stack $\left(04^{0}-12^{0}\right)$ and far angle stack $\left(30^{0}-42^{0}\right)$. Also provided are checkshot data for well Jay 01 in it digital format. Figure 1 is the base map of 'Jay' Field showing well locations and seismic coverage.

Data analysis: Gamma log was used to identify the different lithologies and reservoir zones of interest. Amplitude variations from reservoir tops were mapped from the near to far stacks and trends of Amplitude Variation with Angles were identified. Poisson ratio contrast across lithological interfaces was used to analyze the different seismic amplitude information from the reservoirs as described by (Ostrander, 1984; Allen and Peddy, 1994).

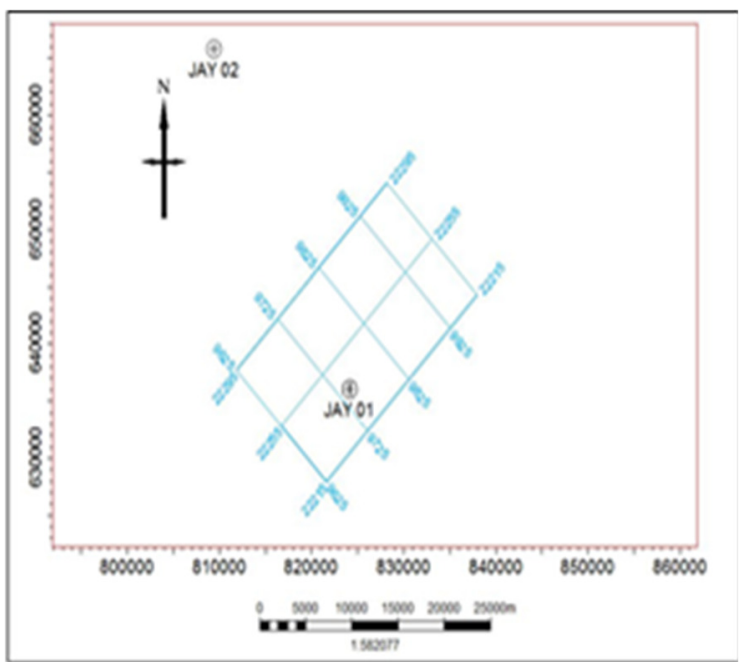

Fig 1: Base map of 'Jay' Field.

Elastic inversion technique by Connolly (1999) and Russell et al, (2006) was adopted in the creation of model seismic volumes at angle ranges of $04^{0}-12^{0}$ and $30^{\circ}-42^{\circ}$. Inverted seismic volume were then generated using the model, compressional velocity, shear velocity, density and the estimated elastic impedance logs. These inverted angle stacks were plotted to highlight areas of gas presence. LambdaMu-Rho (LMR) method of inversion was based on the Lame's parameter of incompressibility $(\lambda)$, rigidity $(\mu)$, and density $(\rho)$, as described by Goodway et al., (1997) where the discrimination of lithologies and fluid types were achieved.

\section{RESULTS AND DISCUSSION}

The results are presented in Figures 2-12 and Table 1. Figs. 2 (a, b) show two groups of sandstone reservoirs based on the deep resistivity (RESD) log response. This log separates brine from hydrocarbon saturated reservoirs. Sands A, B and C are brine fill (Fig. 2a) while Sands D, E, F and G are hydrocarbon bearing zones (Fig. 2b).

The types of hydrocarbon saturating these reservoirs are oil for Sand D while it is gas for Sands E, F and G as reflected in Figs. 2b. At the top of the reservoirs, the generated seismic amplitude maps for Sand F indicate increase in amplitude with angles at the far angle stack (Figs. 3a and 3b) thereby supporting the presence of gas as observed from well logs. Sand G amplitude maps as reflected in Figs. $4 \mathrm{a}$ and $4 \mathrm{~b}$ are characterized with relative reduction in amplitude with angles. 


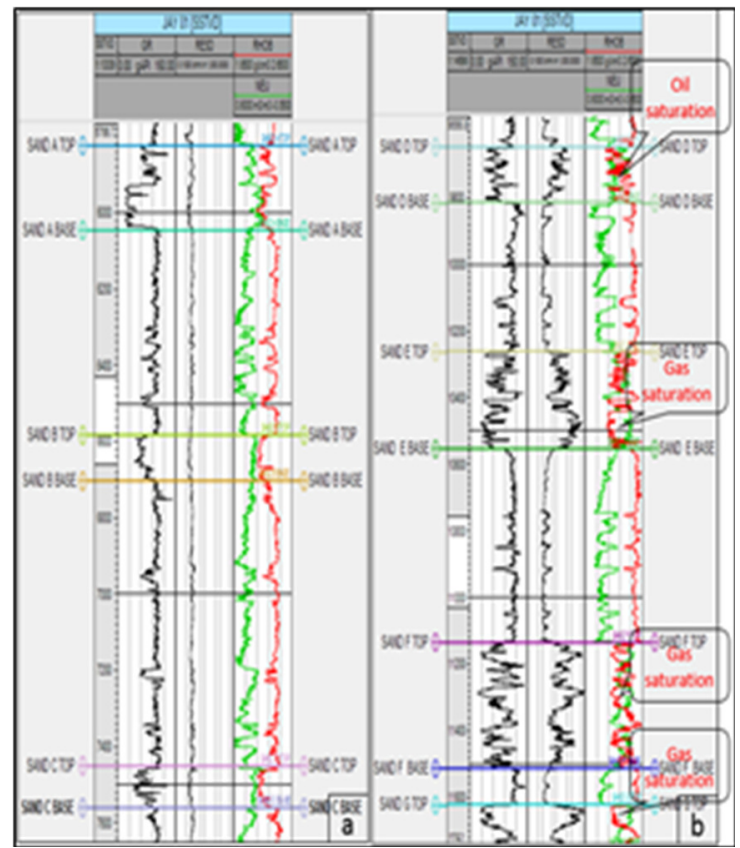

Fig 2: Identified reservoir zones based on gamma log signature for (a) shallow (b) deep seated sandstone reservoirs illustrating the types of fluid saturations.

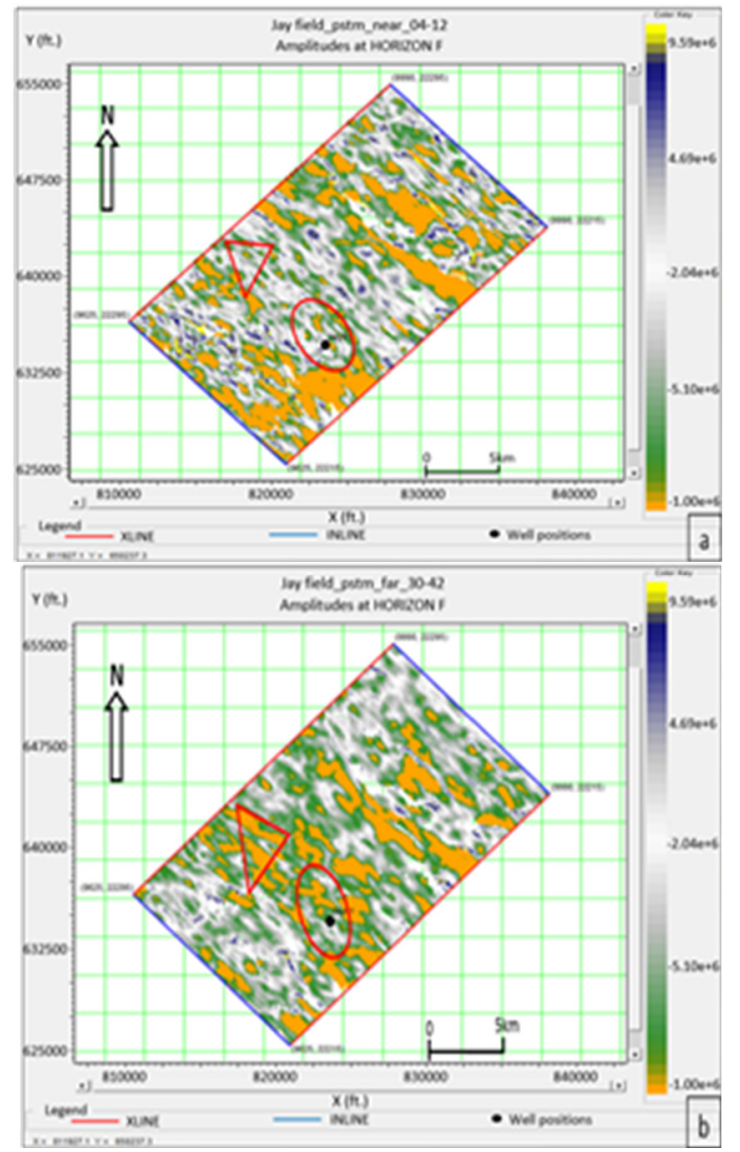

Fig 3: Seismic amplitude map of (a) near angles stack and (b) far angle stack of Sand F.

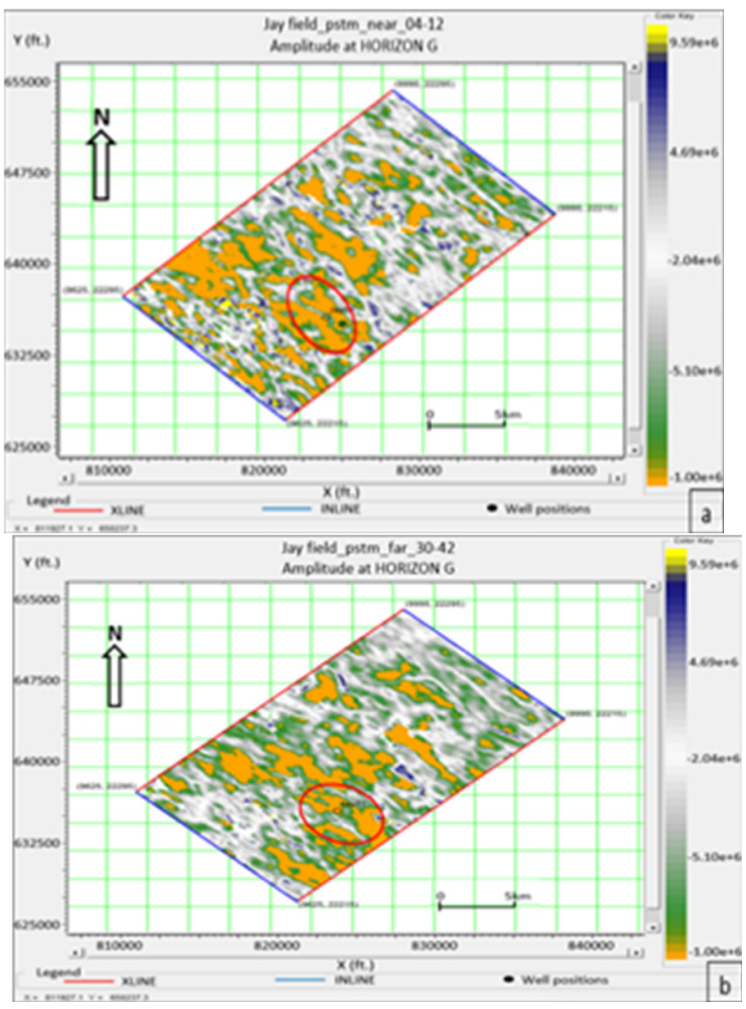

Fig 4: $\quad$ Seismic amplitude map of (a) near angle stack and (b) far angle stack of Sand G.

Figs. 5(a, b) are the Poisson ratio versus P-impedance $\log$ plots of Gas sand $F$ and $G$ respectively. These describe the level of compaction of these reservoirs as well as fluid effect. In Fig. 5a, both impedance and Poisson ratio reduce significantly across the shale/Sand F interface. However, despite reduction in impedance contrast, Poisson ratios remain relatively the same across the interface of shale/Sand G as shown in Fig. 5b. This is why its amplitude decreases with increasing angles as verified by (Allen and Peddy, 1994; Castagna and Swan, 1997). In the plot of elastic impedance logs estimate of near against far angles of Fig. 6, two main zones are identified by the yellow and grey backgrounds. The yellow zone is indicative of sandstone/shaly sandstone, showing a different trend due to the effect of gas saturation. This zone corresponds to Sands E, F and G. Sand D has higher impedance closer to the impedance of shale body which is the second zone with grey background. This crossplot reveals that near angles impedance (acoustic impedance) alone did not sufficiently differentiate Sands F and G from the encasing shale. Fig. 7 is the generated elastic impedance model of the subsurface. It represents an initial guess of the impedance structure. This model shows layers of stratified earth from top of Sand D to Sand G. Sands D, E, F and G are bounded by shale lithologies with lower impedances. 


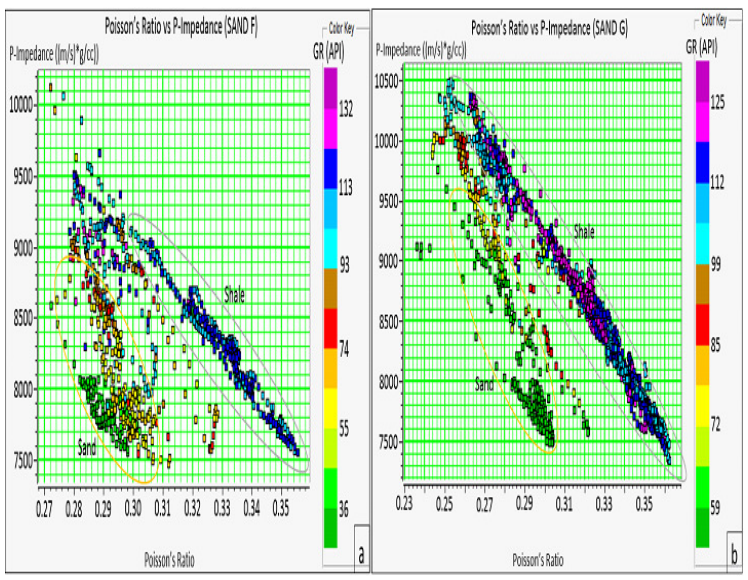

Fig 5: $\quad$ P-impedance versus Poisson ratio crossplot of (a) Sand $\mathrm{F}$ and (b) Sand $\mathrm{G}$ with the respective overlying shale

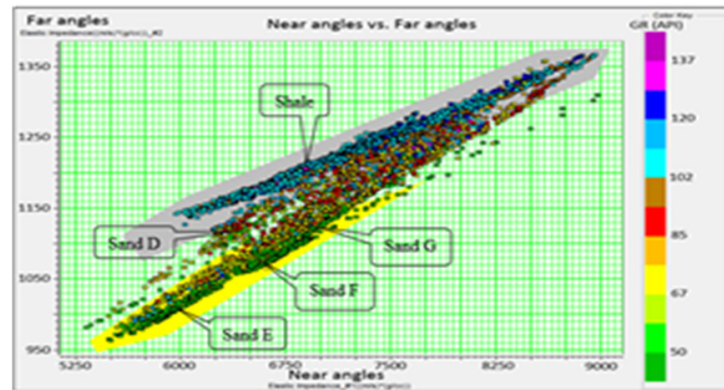

Fig 6: Plot log estimate for the far elastic impedance against near elastic impedance at depth $9500 \mathrm{ft}-12000 \mathrm{ft}$

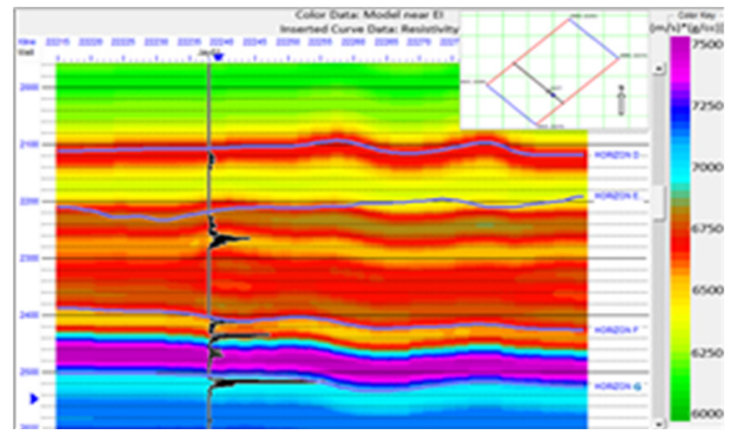

Fig 7: Elastic impedance model for near angle stack.

Figs. 8( $(\mathrm{a}$ and $\mathrm{b})$ are the results of the inverted near and far seismic volumes for Sands E. It reveals AVA effect at the far angles (red ovals). The elastic impedance property around the well of Sand E at the near angle (black oval) has an approximate value of 6200 $\mathrm{m} / \mathrm{s} * \mathrm{~g} / \mathrm{cc}$ (Fig. 8a) and a corresponding value of 1060 $\mathrm{m} / \mathrm{s}^{*} \mathrm{~g} / \mathrm{cc}$ described by the red oval (Fig. $8 \mathrm{~b}$ ) of the far stack. This significantly correlates with the log plot of near versus far impedances described in Fig. 6. These results show that comparable range of elastic impedance is observed at areas indicated by the red triangle and at well location (red oval) of the mapped seismic amplitudes for Sands E. This implies that the possibility of having the gas reservoir extending from the well location to the red triangle of Sand E is very high.

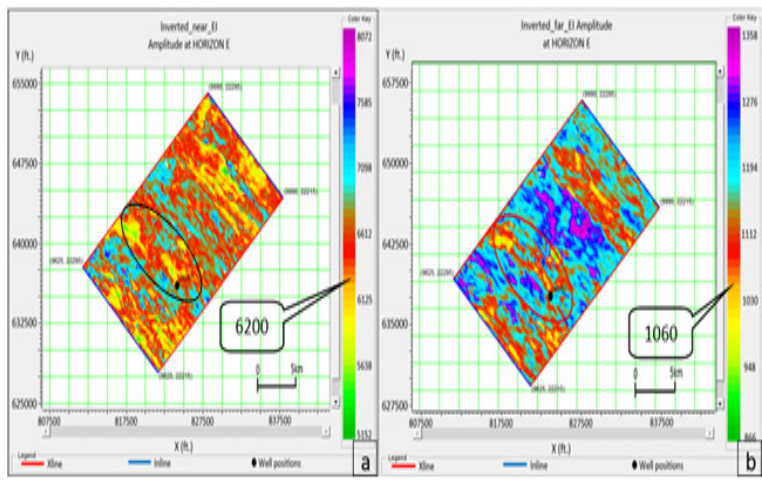

Fig 8: Inverted amplitude result of (a) near stack, black oval; and (b) far stack for S and E showing AVA effect at far angles (red oval).

The crossplot of Mu-rho $(\mu \rho)$ and Lambda-rho $(\lambda \rho)$ $\log$ transforms of the Lambda-Mu-Rho (LMR) analysis is presented in Fig. 9. Sand D which shares close proximity with the brine sands and shale lithologies supports earlier analysis that it is not gas but oil saturated. Sands E, F and G have lower $\lambda \rho$ when compared to the brine sands. It is an indication that the fluid can be compressed, which is a typical characteristic of a gaseous fluid. Moreover, the modulus of rigidity $(\mu \rho)$ is high at Sands E, F and G than in the shallow seated brine saturated sandstone reservoirs and shale lithologies. This is an evidence of the presence of more compressed quartz rich sandstone than the brine sand as substantiated by (Nwajide, 2013; Ogagarue and Anine, 2016). Hence, the coincidence of low $\lambda \rho$ and high $\mu \rho$ signifies the presence of gaseous fluid. The inverted seismic volume of $\lambda \rho$ for the far angle stack is presented in Fig. 10 (lmr_LR inversion). This describes the incompressibility distribution of reservoir rocks for fluid determination from seismic data.

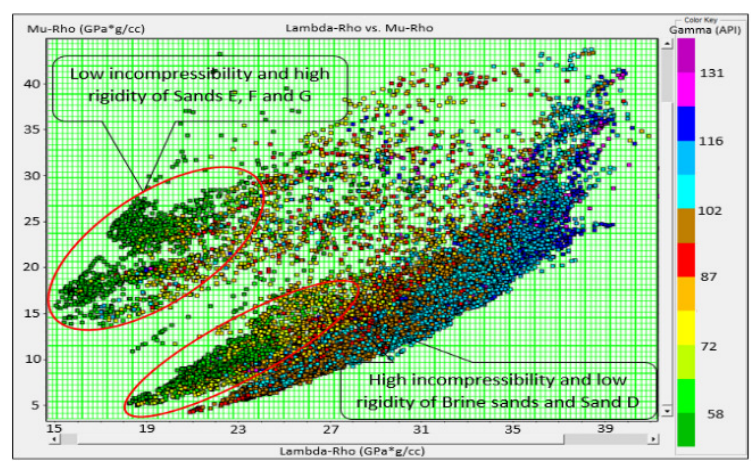

Fig 9: Plot of Mu-rho $(\mu \rho)$ and Lambda-rho $(\lambda \rho)$ logs showing sand and shale lithologies and the variation in the sandstone reservoirs based on dissimilar fluid content 


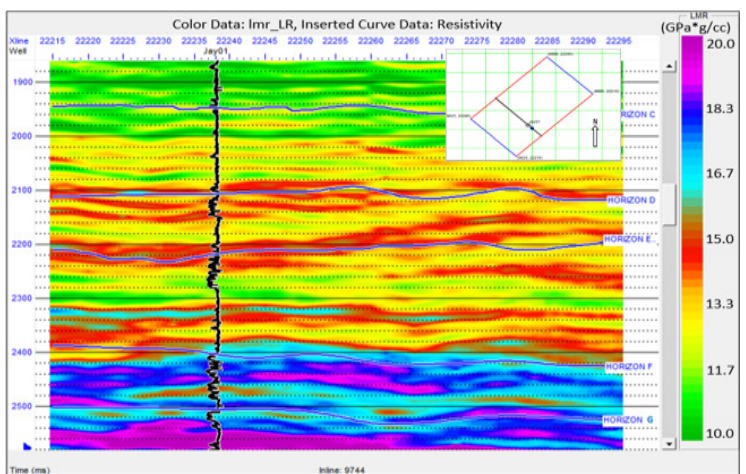

Fig 10: Inverted volume of far angle seismic stack for $\lambda \rho(\mathrm{LR})$ with inserted gamma log.

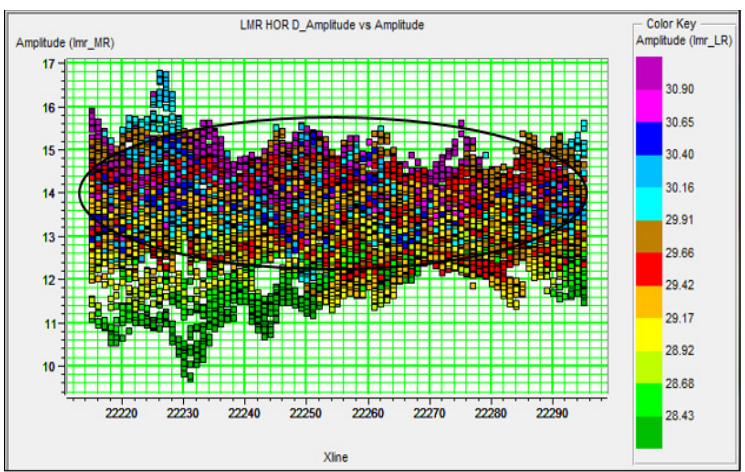

Fig 11: Crossplot of the distribution of seismic inverted $\mu \rho$ and $\lambda \rho$ for Sand D top.

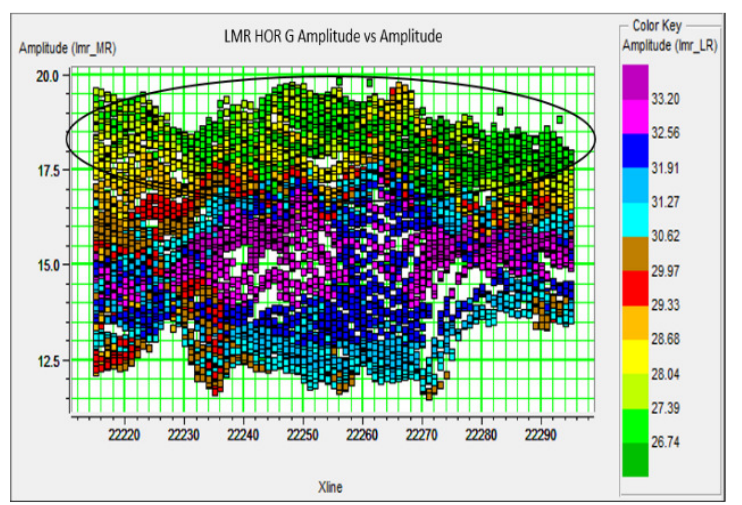

Fig 12: Crossplot of the distribution of seismic inverted $\mu \rho$ and $\lambda \rho$ at Sand G top.

\begin{tabular}{|c|c|c|c|c|}
\hline $\begin{array}{l}\text { Sand } \\
\text { Reservoirs }\end{array}$ & $\begin{array}{l}\text { Empirical Relation } \\
\text { fromwelllog analysis }\end{array}$ & & $\begin{array}{l}\text { Empirical Relation } \\
\text { from inverted seismic } \\
\text { analysis }\end{array}$ & Err \\
\hline & & 0.10 & $\mathrm{MR}=1.01 \mathrm{LR}$ & 0.12 \\
\hline & & 0.10 & & 0.14 \\
\hline & 02 & 0.08 & MI & 0.13 \\
\hline & 74 & 0.17 & MI & 0.12 \\
\hline Sanc & $92 \mathrm{LR}-0.74$ & 0.10 & $\mathrm{MR}=1.70 \mathrm{LR}-40.71$ & 0.29 \\
\hline & & 0.11 & & 0.16 \\
\hline & $\mathrm{MR}=1.22 \mathrm{LR}-1.12$ & 0.06 & $\mathrm{MR}=1.74 \mathrm{LR}-39.26$ & 0.09 \\
\hline
\end{tabular}

The crossplot in Fig. 11 reveals that incompressibility and rock rigidity are both high in Sand D (black oval). This does not show the diagnostic response expected of the presence of gas such that low incompressibility will coincide with high rock rigidity. Throughout this crossline range and around the well location (crossline 22238), high rock incompressibility generally coincides with high rock rigidity. A significant departure from Sand D is observed in Sand G (Fig. 12). Low incompressibility coincides with high rigidity in this reservoir rock (black oval). This is an evidence of gas presence. The generated localized empirical relationships between the $\mu \rho$ and $\lambda \rho$ from well logs and inverted seismics are described in Table 1 for all the identified sandstone reservoirs. These equations reveal a linear trend between $\mu \rho(\mathrm{Y})$ and $\lambda \rho(\mathrm{X})$. In this table are columns for the sand reservoirs, the derived empirical relationship between $\mu \rho$ (MR) and $\lambda \rho$ (LR) and the estimated errors. The increase in the $\lambda \rho$ (LR) coefficient from Sand A to Sand $G$ in the well log empirical relations columns also show that the corresponding intercepts becomes less negative. This is an indication of increase in rock rigidity with depths. It signifies that modulus of rigidity (stiffness) increases with depth, an attribute of quartz rich sandstone reservoirs, while the incompressibility of the reservoirs reduces from brine sands to gas sands.

The inverted seismic empirical relations reflect that both intercept and gradient indicate relative increase from Sand A to G. This shows increase in intercept with depth due to the increase in seismic amplitude that becomes more negative. Therefore, the intercept is mainly an interface function resulting from the change in pore fluid from brine to gas at the deeply buried sandstone reservoirs.

Conclusions: This work has helped to understand the implications of the different reflected amplitudes from hydrocarbon reservoirs and identified locations of possible gas accumulation (red triangles) from angle stacked seismic volume of the 'Jay' Field. The integration of AVA, Elastic impedance and Lambda$\mathrm{Mu}-\mathrm{Rho}$ inversions supports the presence of gas in the identified area away from well location. This also suggests the presence of gas saturation in Sand G despite decrease in amplitude with angles.

Acknowledgement: The authors will like to appreciate Chevron Nigeria Limited through the Department of Petroleum resources for the release of the data set used for this work. We also want to thank the Department of Geosciences, University of Lagos for granting us access to the Geophysics laboratory.

\section{REFERENCES}

Adekanle, A; Enikanselu, PA (2013). Porosity Prediction from Seismic Inversion Properties over 
'XLD' Field, Niger Delta. Am. J. Sci. Ind. Res. 4(1): 31-35.

Allen, JA; Peddy, C (1994). Amplitude variation with offset: Gulf coast case studies. Society of Exploration Geophysics.

Avbovbo, A (1978). Tertiary lithostratigraphy of Niger Delta. American Association of Petroleum Geologists Bulletin, 62: 295-300.

Avseth, P; Mukerji, T; Mavko, G (2005). Quantitative Seismic Interpretation: Applying Rock Physics Tools to Reduce Interpretational Risk: Cambridge University Press.

Castagna, JP; Swan, HW (1997). Principle of AVO crossplotting. The Leading Edge, 16: 337 - 342.

Connolly, P (1999). Elastic Impedance. The Leading Edge, 18 (4): 438 - 452.

Cooke, DA; Schneider, WA (1983). Generalized seismic linear inversion of reflection seismic data. Geophysics, 48, 665 - 676.

Contreras, A; Torres-Verdin, C; Fasnacht, T (2006). AVA simultaneous inversion of partially-stacked seismic amplitude data for spatial delineation of lithology and fluid units deep water hydrocarbon reservoirs in the Central Gulf of Mexico. Geophysics, 71: 41-48.

Ekwe, AC; Onuoha, KM; Osayande, N (2012). Fluid and Lithology Discrimination Using Rock Physics Modelling and LambdaMuRho Inversion: An Example from Onshore Niger Delta, Nigeria. AAPG International Conference and Exhibition.

Goodway, W; Chen, T; Downton, J (1997). Improved AVO fluid Detection and Lithology Discrimination Using

Lame Petrophysical Parameters: " $\lambda \rho "$, " $\mu \rho "$ and " $\lambda / \mu$ " fluid stack, from $\mathrm{P}$ and $\mathrm{S}$ inversions. Soc. Expl. Geophysics, 67th Annual International Meeting, Expanded Abstracts: 183 - 186.
Javaherian, A; Salehi, E; Pour, MA; Farajkhah, NK; Arabani, MS (2013). Quantitative seismic prestack analysis of potential gas hydrate resources in the Makran Accretionary Prism, offshore Iran. Marine and Petroleum Geology, 48: 160 - 170.

Nwajide, C (2013). Geology of Nigeria's sedimentary basins. CSS press.

Ogagarue, DO; Anine, LA (2016). An Integration of Rock Physics, AVO Modeling and Analysis for Reservoir Fluid and Lithology Discrimination in A Niger Delta Deep Water Block. J Appl. Geol. Geophysics, 4(2): 36 - 46.

Ostrander, WJ (1984). Plane wave reflection coefficients for gas sands at non-normal angles of incidence. Geophysics, 49: 1637-1648.

Russell, B; Hampson, D; Bankhead, B (2006). An inversion primer. Canadian Soc. Explor. Geophysicist Recorder, 31(10): 101 - 108.

Simm, R. (2005). The essentials of rock physics for seismic amplitude interpretation. Rock Physics Associates.

Simm, R; Bacon, M (2014). Seismic Amplitude. An interpreter's handbook. Cambridge University Press.

Stacher, P (1995). Present understanding of the Niger Delta hydrocarbon habitat. In: Tuttle, M; Charpentier, R; Brownfield, M. The Niger Delta Petroleum System: Niger Delta Province, Nigeria, Cameroon, and Equatorial Guinea, Africa. USGS, Open File.

Veeken, PC. Da Silva, M. (2004). Seismic inversion methods and some of their constraints First break, 22 (6), $47-70$. 